\title{
PEMANFAATAN SIMBOL SUCI HINDU DALAM INDUSTRI PARIWISATA BALI
}

\author{
Oleh: \\ I Gusti Ketut Widana \\ Fakultas Pendidikan Agama dan Seni UNHI Denpasar \\ Email: igustiketutwidana1805@gmail.com
}

\begin{abstract}
In fact, whatever exists, both outside and inherent in the human self is also a series of symbolic nodes which, when interpreted, will puncture or bring about various meanings. Meanings derived from the results of observation, reading, appreciation or even agreement on what is behind the symbols. The essence of the symbol is not merely in what appears in the form of material matter, but rather to what is "hidden" behind the embodiment itself. Likewise with tools related to the implementation of ceremony / upakara yadnya very rich symbol, and certainly has a sacred value (sacred) which is only limited to be used in establishing a relationship to Hyang Widhi bhakti and all his manifestations. If then because of the unique aesthetic look of the media the sacred symbol is then used for the benefit of the tourism industry, as long as it remains in the context as it is displayed in terms of the implementation of yadnya, certainly not a problem. But if the sacred symbol media is only manipulated to be taken in aesthetic terms and then packaged as part of commercialization, then in addition to the risk of harassment and even desecration, is also likely to rip the religious emotions of Hindus who strongly believe the sanctity of the symbol as a sacred device that is oriented transcendental, The appearance of financially sourced material for sale.
\end{abstract}

Keywords: holy symbol, Bali tourism

\section{Abstrak}

Pada kenyataannya, apapun yang ada, baik di luar dirinya maupun yang melekat pada diri manusia adalah juga serangkaian simpul-simpul simbol yang apabila ditafsir akan menyembulkan atau memunculkan bermacam makna. Makna yang berasal dari hasil pencermatan, pembacaan, penghayatan atau bahkan kesepakatan atas apa yang ada dibalik simbol-simbol itu. hakikat simbol adalah bukan semata-mata terletak pada apa yang tampak dalam bentuk materi yang berwujud, tetapi lebih kepada apa yang "berada" (tersembunyi) dibalik perwujudan itu sendiri. Begitupun dengan piranti terkait pelaksanaan upacara/upakara yadnya yang sangat kaya simbol, dan pastinya memiliki nilai kesucian (sakral) yang hanya terbatas dipergunakan dalam menjalin hubungan bhakti kehadapan Hyang Widhi beserta segala manifestasi-Nya. Jikalau kemudian karena tampilan unik bernuansa estetis media simbol suci tersebut lalu dimanfaatkan untuk kepentingan industri pariwisata, sepanjang tetap dalam konteks sebagaimana adanya ditampilkan dalam kaitan pelaksanaan yadnya, tentu tidak menjadi masalah. Namun apabila media simbol suci hanya dimanipulasi untuk diambil segi-segi estetis kemudian dikemas sebagai bagian dari komersialisasi, maka selain berisiko terhadap pelecehan bahkan penodaan, juga berpeluang mengoyak emosi keagamaan umat Hindu yang sangat meyakini kesucian simbol itu sebagai piranti sakral yang berorientasi transendental, tidak sekedar tampilan material berutilitas finansial untuk dijual.

Kata kunci: simbol suci, pariwisata Bali 


\section{PENDAHULUAN}

Sejarah kehadiran manusia di muka bumi, melahirkan peradaban. Suatu masa dimana manusia telah mengalami fase kamajuan sebagai homo sapiens, dibandingkan dengan zaman awal sebagai summo primat - primata tertinggi. Dalam perjalanannya, peradaban melahirkan kebudayaan, saat mana manusia sudah memiliki kemampuan mengekspresikan "cipta-rasa dan karsa" dengan segala bentuk, fungsi dan maknanya.

Mengacu Koentjaraningrat (1980), kebudayaan meliputi tiga wujud, yaitu : 1) ide/gagasan atau konsep; 2) aktivitas/perilaku dan; 3) benda/artefak atau tinggalan yang umumnya berupa benda, seperti alat peralatan. Beranjak dari mencermati realita alam dengan segala fenomena dan dinamikanya, merangsang pikiran manusia hingga kemudian melahirkan ide/gagasan atau konsep. Ide/gagasan atau konsep itu selanjutnya diperilakukan, terus menerus sebagai suatu kebiasaan yang akhirnya disepakati menjadi apa yang belakangan disebut "adat-istiadat". Adat-istiadat inilah yang menjadi bagian penting dari aktivitas, kreativitas dan produktivitas kebudayaan.

Ditilik dari unsur-unsurnya, menurut konsep B. Malinowski (dalam Soelaeman, 2007 : 23) kebudayaan di dunia mempunyai tujuh unsur universal yaitu : 1) Bahasa; 2) Sistem teknologi; 3) Sistem mata pencaharian; 4) Organisasi sosial; 5) Sistem pengetahuan; 6) Religi; dan 7) Kesenian. Sementara jika ditilik dari hakikatnya, kebudayaan itu memiliki dua segi, yaitu : 1) Segi kebendaan; yang meliputi segala benda buatan manusia sebagai perwujudan dari akalnya yang hasil-hasilnya dapat diraba; dan 2) Segi kerohanian, terdiri atas alam pikiran dan kumpulan perasaan yang tersusun teratur. Keduanya tidak dapat diraba, hanya penjelmaannya saja dapat dipahami dari keagamaan, kesenian, kemasyarakatan, dan sebagainya (Soekmono, 1973 : 9)

Terkait dengan segi-segi kebudayaan di atas, dalam perkembangannya mengalami pemilahan cukup jelas, bahwa apa yang disebut dengan "kebudayaan" lebih menampakkan unsur-unsur kebendaannya guna memenuhi kebutuhan hidup secara jasmani/ragawi. Sedangkan segi kebudayaan yang berkaitan dengan "kerohanian" tiada lain hal-hal yang bertalian erat dengan "kepercayaan/keyakinan", menjadi pondasi dari apa yang belakangan disebut "religi/agama".

Kebudayaan berusaha menjawab pertanyaan seluas wilayah dan sejauh kedalaman kemanusiaan manusia. Sementara apabila kebudayaan sudah tidak lagi mampu menjawab pertanyaan-pertanyaan yang menyangkut kemanusiaan manusia, maka religi/agama yang berdasar iman/kepercayaan/keyakin terhadap alam transenden yang menjawanya.

\section{PEMBAHASAN}

\subsection{Agama dan Kebudayaan}

Kata "Agama" merupakan terjemahan bahasa Sanskerta Dharma. Kata Agama berasal dari akar kata 'a' yang berarti 'tidak' dan 'gam' yang artinya 'pergi'. Dengan kata lain Agama dapat diartikan 'sesautu yang tidak pergi', tidak berubah atau tetap, langgeng (abadi), tiada lain hanyalah Hyang Widhi beserta ajarannya (PHDI, 2013 : 42). Sedangkan kata "kebudayaan", menurut Koentjaraningrat (dalam Sulaeman, 2007 : 21) berasal dari kata Sanskerta 'budhayah', bentuk jamak dari kata 'budhi' yang berarti 'budi' atau 'akal'. Jadi kebudayaan dapat diartikan 'hal-hal yang bersangkutan dengan akal', yang dalam perkembangannya sering diberi arti 'hasil dari cipta, karsa dan rasa manusia.

Kedua istilah itu, agama dan kebudayaan memang berbeda dan dapat dipilah, tetapi dalam pelaksanaannya satu sama lain saling bertautan, hingga tidak bisa dipisahkan. Sebab apa yang diperintahkan oleh ajaran-Nya, akan dilaksanakan oleh umat manusia yang adalah makhluk berbudaya. Sehingga, oleh karena antara praktik keagamaan dengan aktivitas kebudayaan terjalin erat sebagai satu kesatuan dalam kehidupan manusia, termasuk dalam kapasitasnya sebagai umat beragama, menjadikan apa yang dilaksanakan sebagai perintah agama seperti tampak sebagai kegiatan budaya. Begitu pula sebaliknya, apapun yang dilakukan sebagai kegiatan budaya acapkali sekaligus berkaitan dengan aktivitas keagamaan.

Intinya, sebagai masyarakat yang sosialistis religius, lebih-lebih bagi umat Hindu, hampir 
tidak ada suatu kegiatan yang dilakukan lepas dari dimensi agama dan kebudayanya. Agama menjadi jiwa atau roh kebudayaan, sementara kebudayaan itu sendiri sebagai unsur material yang tampak dalam pencandraan panca indra. Ini berarti, hampir setiap kegiatan agama senantiasa dimanifestasikan ke dalam aktivitas kebudayaan, sementara setiap kegiatan kebudayaan sudah tentu dijiwai oleh ajaran agama.

Boleh jadi karena begitu lebur dan luluhnya antara agama dan kebudayaan, seringkali keberadaan atau kehadiran keduanya disalahmengertikan. Sehingga, tidak jarang agama Hindu yang kental dengan pelaksanaan tradisi adat dan budayanya, dinilai sebagai "agama budaya", yang dipahami sebagai agama "buatan" manusia, yang tidak berasal dari wahyu Tuhan. Tentu saja, penilaian dan pemahaman dangkal model begini, teramat keliru, salah besar dan sangat sesat sekaligus bisa menyesatkan. Sejatinya, seperti halnya agama resmi lainnya, agama Hindu adalah agama wahyu Tuhan (Daiwi Wak) yang telah disuratkan di dalam kitab suci Weda, oleh para Resi sebagai penerima, penghimpun dan penulis ajaran Tuhan itu.

Bahwa praktik agama Hindu kaya dengan aktivitas kebudayaan, tentu tidak dapat dimungkiri, karena pelaksanaan ajaran agama Hindu memang dimulai dari tingkatan kasat mata yang tampak pada aktivitas kebudayaan yang dicirikan dengan adanya "acara/upacara/upakara yadnya” yang sarana prasarananya bersifat "materi". Setelah penampakkan unsur materi lewat bentuk bebanten, baru meningkat ke bagian "isi" (susila/etika), hingga memuncak pada pendalaman "inti" (tattwa/filsafat). Ketiga elemen (Tattwa, Susila dan Acara/Upacara) inilah yang menjadi kerangka dasar umat/agama Hindu untuk memperkokoh sraddha-bhaktinya kehadapan Tuhan/Hyang Widhi.

Dalam pelaksanaannya, ketiga elemen/unsur itu sulit sekali dipisahkan, meski bisa dibedakan. Sebab Tattwa, Susila dan Acara/Upacara, dalam pelaksanaannya saling menjiwai dan melingkupi. Hanya saja, oleh karena yang paling tampak menonjol adalah unsur budayanya, seakan-akan agama Hindu itu merupakan agama budaya. Padahal yang benar, melalui budayalah agama Hindu dilaksanakan. Sehingga, istilah yang tepat bukan "agama budaya" melainkan "budaya agama", yaitu suatu bentuk aktivitas budaya yang sejatinya merupakan penga- malan ajaran agama Hindu.

\section{2 "Agama Pariwisata"}

Masyarakat Bali sangat beruntung mempunyai Pulau Bali yang meskipun kecil tetapi namanya menjadi "besar", dikenal dan terkenal di seantero dunia. Tetapi sebagaimana hukum rwabhineda berjalan, di balik keberuntungannya, Pulau Bali dengan orang-orang Balinya yang notabene umat Hindu juga tak terhindar dari sisi "buntungnya". Lantaran terlalu mengikuti bahkan berambisi mengejar keberuntungan di sektor pariwisata, seakan-akan apapun yang berpotensi untuk dijual dan menguntungkan, akhirnya dikomersilkan. Tak terkecuali hal-hal yang sebenarnya tidak patut dijadikan sebagai komoditi pariwisata, yaitu segala yang berkaitan dengan kesakralan agama. $\mathrm{Mu}-$ lai dari upacara yadnya dengan upakara bebantennya, seni wali, keberadaan Pura yang merupakan tempat suci, termasuk simbol-simbol suci agama Hindu.

Di tengah derasnya arus globalisasi yang membawa percepatan terhadap pembangunan, sepertinya tidak ada lagi hal yang tidak bisa dijual lagi di Bali demi kemajuan industri pariwisata. Semua serba dibuat menjadi "bisa/boleh" demi dan atas nama pariwisata. Boleh jadi pandangan inilah yang melahirkan pernyataan, bahwa di Bali sekarang ini umat Hindunya sudah menjadikan pariwisata sebagai "agama" baru. Suatu bentuk keyakinan (sebagian) masyarakat Bali yang memandang, hanya dengan pariwisatalah Bali bisa mencapai kemajuan, khususnya material-finansial. Tanpa pariwisata Bali seolah akan bangkrut, begitu seringkali kalangan elite membuat statement (Widana, 2012: 15).

Padahal, dari sudut pandang (kepentingan) agama yang menjadi pondasi kekuatan spiritual Bali, bisa jadi karena pariwisatalah $\mathrm{Pu}-$ lau Bali yang sakral (suci), dengan orang Bali (Hindu) yang berjiwa sosio religius justru menjadi ambisius mengejar keuntungan material-finansial. Lantaran ambisi mengejar target devisa negara, meningkatkan pendapatan asli daerah, keuntungan besar pelaku pariwisata, akhirnya Pulau Bali dijadikan sebagai "barang dagangan", seperti komoditi lalu dikomersilkan, tepatnya dijual bahkan adakalanya terkesan diobral.

Jangan heran, tidak hanya potensi alami, 
aktivitas religi/rohani, dengan serangkaian ritual keagamaannya, dan kreasi seni budaya yang menyertainya, termasuk hal-hal yang berhubungan dengan kehidupan sosio-kultural masyarakat Bali yang notabene beragama Hindu, dengan mudahnya dipromosikan untuk dijual demi memenuhi selera pasar pariwisata. Banyak contoh dapat disebutkan, diantaranya :

1) Pura dijadikan sebagai objek wisata. Hanya dengan membeli karcis, para turis dengan leluasa masuk hingga ke jeroan/ utama mandala Pura yang sejatinya merupakan area yang paling disucikan.

2) Menawarkan dan atau menjual paket upacara yadnya yang bersifat sakral sebagai acara seremonial, seperti paket upacara perkawinan ala Hindu, tetapi dilakoni pasangan non-Hindu, termasuk untuk pasangan sejenis. Ada juga yang menjual ritual besar seperti upacara ngaben untuk konsumsi tayangan/siaran televisi, tak terkeucali ritual panglukatan, piodalan, termasuk paket liburan Nyepi, dll

3) Memanipulasi dengan cara memodifikasi sarana/materi/benda/alat peralatan terkait ritual Hindu lalu dikomersilkan sebagaimana halnya barang kerajinan biasa. Contoh wujud sosok Dewa-Dewi dalam kepercayaan Hindu disulap menjadi pernak-pernik aksesoris, mulai dari bentuk gantungan kunci hingga patung-patung yang dibuat kodian. Bahkan sosok Dewa Ganesa ada juga yang memisualisasikannya ke dalam bentuk tatto pada bagian tubuh turis yang sangat merendahkan nilai kesakralannya, karena ditatto di bagian kelamin, pantat, paha, perut, dsb. Termasuk keberadaan "Aksara Suci" Hindu seperti "Omkara", dan lambang identitas Hindu "Swastika", tidak jarang juga dimanipulasi melalui modifikasi hingga menjadi bentuk produk seni budaya.

4) Kesenian Bali yang berbasis kultural dan berdimensi ritual-sakral, serta berorientasi transendental (niskala) dengan mudah dan murahnya disulap menjadi kesenian komersial berorientasi material-finasial, dipertunjukkan hanya sebagai tontonan, dengan meninggalkan tuntunan filosofis dan landasan etis.

5) Membiarkan para investor dengan leluasa merambah kawasan-kawasan suci
(Pura) untuk membangun fasilitas pariwisata, seperti hotel, villa, bungalo, lapangan golf, cafe, tempat hiburan, dll, meskipun sudah ada "bhisama" tentang radius kesucian Pura, tetapi tetap saja ada yang melanggar. Pelanggaran mana acapkali terjadi karena kolaborasi simbiosis mutualisme antara pihak pengusaha (investor) dengan kepentingan pemerintah yang dalam hal ini diwakili pemangku/pejabat selaku penguasa yang mempunyai kewenangan merekomendasikan dan mengeluarkan perijinan.

6) Dan lain-lain

\subsection{Kebudayaan dan Simbol-Simbol Aga- ma}

Simbol-simbol religi/agama adalah fakta kebudayaan, wujudnya dapat berbentuk bendabenda dan juga non benda. Tetapi religi/agama bukanlah kebudayaan, sebab berada dalam tataran abstrak (bathin) yang inti dan sifatnya berhubungan dengan kepercayaan/keyakinan (sradha). Manifestasi sraddha agar benar-benar tampak nyata itulah sebagai cara-cara menjalankan agama, yang diantaranya dapat melahirkan simbol-simbol (Artadi, 2011 : 35-36).

\subsubsection{Arti dan Makna Simbol dalam Aga- ma Hindu}

Kata 'simbol' (Inggris : symbol) mengandung arti : untuk sesuatu atau juga menggambarkan sesuatu, khususnya untuk menggambarkan sesautu yang immaterial, abstrak, ustu idea, kualitas, tanda-tanda suatu objek, proses dan lain-lain (Coulson, 1978: Vol. II).

Pendapat lain, kata 'simbol' berasal dari bahasa Greek, "sum-ballo" yang mengandung arti "saya bersatu bersamanya", ":penyatuan bersama". Apakah yang dapat disatukan bersama dalam simbol itu, di satu pihak adalah bentuk, dan nilai harfiah, di pihak lain kehidupan yang membimbing kita (Reede, 1989 : 31). Sementara itu, Sekhar Gosh (1990 : 58) menyatakan bahwa kata 'simbol' berasal dari kata "symbolon" (dalam bahasa Greek) yang berarti tanda dan dengan tanda itu seseorang mengetahui atau mengambil kesimpulan tentang sesuatu. Di dalam bahasa Sanskerta kata simbol disebut "pratika" yang mengandung arti "yang datang ke depan, yang mendekati". Dengan demikian kata 
ini mengandung makna menunjukkan, menampilkan atau menarik kembali sesuatu dengan analogi kualitas kepemilikan atau dengan mengasosiasikan ke dalam fakta atau pikiran.

Lebih lanjut tentang simbol, Swami Sivananda (1993 : 154) menambahkan, dalam contoh Pratima atau patung merupakan pengganti. Gambar atau arca pada sebuah Pura, walaupun terbuat dari batu, kayu, kertas atau logam sangat berharga bagi seorang penyembah, karena hal itu menandakan ada hubungan dengan yang disembah, Tuhan Yang Maha Esa atau manifestasi-Nya. Gambar atau arca itu menggantikan sesautu yang ia sucikan dan abadi, seperti halnya bendera merah putih misalnya yang sejatinya hanya potongan kain kecil, namun sangat mengghugah emosi dan membangkitkan spirit perjuangan, hingga rela mengorbankan raga dan jiwa untuk merebut dan atau mempertahankannya.

Untuk memahami simbol-simbol keagamaan, Eliade (2000 : 184) dalam tulisannya "Kuncikunci Metodologis dalam Studi Simbolisme Kegamaan" menyatakan bahwa kunci pertama untuk memahami simbol-simbol keagamaan adalah bagaimana agar dunia "berbicara" atau "mengungkapkan diri" melalui simbol-simbol, dan bukan dalam bahasa utilitarian atau objektif. Simbol-simbol bukan sekedar cerminan realitas objektif, ia mengungkapkan sesuatu yang lebih pokok dan lebih mendasar.

Istilah simbol juga berarti satu hal atau keadaan yang merupakan pengantaraan pemahaman terhadap objek. Manifestasi karakteristik simbol tidak terbatas pada isyarat fisik, tetapi dapat juga pada berwujud penggunaan kata-kata, yakni simbol suara yang mengandung arti bersama serta bersifat standar. Singkatnya, simbol berfungsi memimpin subjek kepada objek. Dalam makna tertentu, simbol acapkali memiliki makna mendalam, yaitu suatu konsep yang paling bernilai dalam kehidupan masyarakat.

Pada kenyataannya, apapun yang ada, baik di luar dirinya maupun yang melekat pada diri manusia adalah juga serangkaian simpul-simpul simbol yang apabila ditafsir akan menyembulkan atau memunculkan bermacam makna. Makna yang berasal dari hasil pencermatan, pembacaan, penghayatan atau bahkan kesepakatan atas apa yang ada dibalik simbol-simbol itu. Jadi, hakikat simbol adalah bukan sematamata terletak pada apa yang tampak dalam ben- tuk materi yang berwujud, tetapi lebih kepada apa yang "berada" (tersembunyi) dibalik perwujudan itu sendiri. Dan simbol itu sendiri hanyalah sebatas penuntun tentang sesuatu makna yang kemudian sepatutnya direalisasikan ke dalam bentuk sikap ataupun perilaku.

Berdasarkan paparan di atas, maka simbolsimbol dalam agama Hindu dengan berbagai bentuk, wujud, nama dan fungsinya mengandung arti untuk medekatkan umat kepada yang dipuja, yakni Tuhan Yang maha Esa, manifestasiNhya, para Devata, Roh-Roh para Rsi, dan Roh leluhur yang telah disucikan sesuai dengan ajaran Hindu (PHDI, 2013 : 67).

\subsubsection{Bentuk Simbol dalam Agama Hindu}

Bila diamati dengan seksama, ditemukan berbagai bentuk simbol-simbol keagamaan Hindu yang sesungghunya bermanfaat sebagai media mendekatkan diri kepada Tuhan yang Maha Esa. Berbagai simbol-simbol keagaman itu dari bentuk dan bahannya yang sangat sederhana hingga kompleks dapat dijumpai penjelasan atau keterangannya dalam kitab suci Weda dan susastra Hindu, termasuk dalam berbagai lontar yang diwarisi di Bali, yang pada kesemua itu pada intinya adalah sebagai bentuk penggambaran Tuhan Yang Maha Esa dengan segala manifestasi-Nya.

Bentuk penggambaran Tuhan Yang Maha Esa beserta manifestasi-Nya itu disebut Citradewa$t a$, yang jika dirinci dapat dibagi menjadi :

1) Berbentuk manusia dengan segala kelebihannya, seperti bertangan empat, delapan atau dua belas, bermata tiga, dll. Penggunaan simbol manusia baik laki-laki dan wanita, atau setengah laki dan wanita (ardhanareswari) terutama ditujukan kepada para Devata, baik Deva-Deva atau Devi-Devi, termasuk sosok Apsara (Vidyadara) dan Apsari (Vidyadari), dll.

2) Berbentuk binatang, misalnya berwujud Barong Ket sebagai simbol Sang Hyang Siwa, Barong Bangkung simbol Wisnu, lalu Naga Taksaka simbol Sang Hyang Siwa, Naga Basuki simbol Sang Hyang Visnu, dll

3) Berbentuk setengah manusia dan setengah binatang, seperti Ganesa, putra Sang Hyang Siva yang lahir dari Devi Uma; lalu Deva Hayagriva, berbadan manusia den- 
gan kepala kuda; dll.

4) Berbentuk manusia berkepala tumbuhtumbuhan, misalnya pohon Soma, pohon Kha, dll, hanya saja simbol sepertri ini tidak begitu dikenal di Bali.

5) Berbentuk benda-benda atau huruf tertentu, misalnya matahari atau cakram (roda) simbol Sang Hyang Surya; bulan simbol Devi candra, lalu huruf suci Omkara simbol Tuhan Yang Maha Esa; Swastika simbol keselamatan, Canang simbol sthana Devata, Daksina simbol Deva Brahma, Keangen simbol Ardhanareswari (Purusa-Pradhana), dll.

Bagi umat Hindu, semua bentuk simbol itu dapat menimbulkan getaran batin dalam dirinya lalu dirasakan dan diyakini sebagai sarana mendekatkan diri dengan Tuhan Yang Maha Esa beserta segala manifestasi-Nya (PHDI, 2013 : 67-69)

\subsubsection{Sakralisasi dan Fungsi Simbol}

Setelah terwujudnya sebuah bentuk simbol (arca, pratima, Pura, banten, dll), baik yang langsung terjadi secara alamiah ataupun yang secara sengaja dibuat (oleh undagi, sangging, seniman, sarati), maka agar dapat difungsikan sebagai sarana ritual dan bersifat sakral, patut melalui prosesi samskara/sangaskara, misalnya melalui upacara "prayascita, pamlaspas, ngenteg linggih dan atau pasupati", yang berintikan pada proses sakralisasi atau transendensi unsur/elemen materi agar menjadi bernilai dan berfungsi suci.

Adapun fungsi simbol-simbol suci keagaman Hindu itu adalah :

1) Meningkatkan dan memantapkan Sraddha (keyakinan/keimanan) umat Hindu dalam rangka menumbuhkan rasa Bhakti (pengamalan) sehingga terbentuk kepribadian luhur dengan perilaku unggul.

2) Menumbuhkembangkan dan tetap terpeliharanya nilai-nilai seni budaya, dengan berbagai jenis, bentuk dan fungsinya yang berkorelasi sebagai pendukung kegiatan upacara keagamaan Hindu (ritual yadnya).

3) Memupuk rasa kebersamaan umat Hindu dalam mewujudkan sarana pemujaan, terutama dalam kaitannya dengan sakralisasi sekaligus memungsikan simbolsimbol keagamaan tersebut dalam koridor kesucian dan atau kesakralan.
Demikian antara lain fungsi dari simbol-simbol agama Hindu yang setelah difungsikan dengan rangkaian upacara tertentu, maka simbolsimbol tersebut tidak lagi eksis sebagai benda biasa, tetapi sudah menjadi "sesautu" yang hidup, berjiwa, mengandung daya spiritual guna memantapkan sraddha dan bhakti. Melalui simbol itu pula umat selaku pemuja atau penyembah Tuhan Yang Maha Esa/Hyang Widhi merasa didekatkan bahkan dipersatukan secara emosional, sehingga menjadikan dirinya jauh lebih religius.

Bahkan ketika suatu simbol yang dalam pencermatan panca indra tampak sebagai ben$\mathrm{da} /$ materi, sesungguhnya hal itu sudah menjadi bagian dari kebudayaan spiritualitas. Kebudayaan dengan produk cipta rasa karsa yang berorientasi pada dimensi spiritual, sekaligus bertujuan menstimulus kesadaran bhakti kepada Tuhan Yang Maha Esa/Hyang Widhi. Demikianlah, bagi seorang umat Hindu, selaku penyembah dan atau pemuja yang telah memiliki kesadaran spiritual tidak akan pernah ragu melakukan persembahan atau persembahyangan dihadapan media berbentuk Palinggih, Arca, Pratima, upakara bebanten, dan sarana lainnya yang dikonsepsikan sebagai simbol suci Hindu.

\subsection{Klasifikasi Simbol-Simbol Agama Hin- du dan Budaya}

Merujuk pada paparan di atas, setidaknya dapat dibuat klasifikasi atau pengkatagorian terhadap "sesuatu" itu dikatakan sebagai simbol-simbol agama Hindu, atau hanya sebatas sebagai simbol budaya. Klasifikasi/katagori simbol-simbol dimaksud, dibedakan atas dasar arti/makna dan fungsinya, apakah semata-mata untuk kepentingan ritual keagamaan, atau dalam hal tertentu bisa/boleh dipergunakan sebagai bagian kegiatan budaya. Meskipun disadari antara kegiatan agama dan budaya seringkali bersinergi, namun satu sama lain yang berbeda itu nyaris sulit dipisahkan, sebab keduanya saling melingkupi dan menjiwai perilaku

umat Hindu.

Dibawah ini dicoba untuk membuatkan klasifikasinya, setidaknya sebagai pengetahuan awal untuk bisa dengan mudah memilah dan memilih, hal-hal mana yang dapat dikatagorikan sebagai simbol-simbol Hindu, sehingga diluar itu dapat diletakkan posisinya sebagai bagian dari simbol aktivitas kebudayaan. 


\begin{tabular}{|c|c|c|c|c|c|}
\hline NO & JENIS SIMBOL & KATAGORI & SIFAT & PERUNTUKAN & CONTOH \\
\hline 1 & $\begin{array}{l}\text { Pura/ } \\
\text { Kahyangan }\end{array}$ & Sakral & $\begin{array}{l}\text { Suci, transen- } \\
\text { dental }\end{array}$ & $\begin{array}{l}\text { Sebagai tempat } \\
\text { suci melak- } \\
\text { sanakan keg- } \\
\text { iatan Upacara } \\
\text { yadnya }\end{array}$ & $\begin{array}{l}\text { Pura Besakih, } \\
\text { Pura Desa, } \\
\text { Puseh dan } \\
\text { Dalem, Pura } \\
\text { Tirtha Empul }\end{array}$ \\
\hline 2 & $\begin{array}{l}\text { Upacara } \\
\text { yadnya, } \\
\text { beserta } \\
\text { sarana/alat } \\
\text { peralatan lain } \\
\text { yang } \\
\text { menyertai }\end{array}$ & $\begin{array}{l}\text { Sakral, } \\
\text { Ritual, } \\
\text { Media bhakti }\end{array}$ & $\begin{array}{l}\text { Suci, imanensi } \\
\text { (materialisasi) }\end{array}$ & $\begin{array}{l}\text { Sebagai sarana } \\
\text { persembahan } \\
\text { dan atau perse- } \\
\text { mbahyangan }\end{array}$ & $\begin{array}{l}\text { Banten Canang, } \\
\text { Soda, Pajati, Ge- } \\
\text { bogan }\end{array}$ \\
\hline 3 & $\begin{array}{l}\text { Tuhan dan } \\
\text { manifestasi- } \\
\text { Nya }\end{array}$ & $\begin{array}{l}\text { Ikon theologis, } \\
\text { penggambaran } \\
\text { "sosok" yang } \\
\text { disembah/ } \\
\text { dipuja }\end{array}$ & $\begin{array}{l}\text { Suci, magis, } \\
\text { mistis, tran- } \\
\text { sendental, } \\
\text { spiritual }\end{array}$ & $\begin{array}{l}\text { Sebagai media } \\
\text { bhakti } \\
\text { Sebagai alat } \\
\text { konsentrasi }\end{array}$ & $\begin{array}{l}\text { Acintya; Arca } \\
\text { Brahma, Wisnu, } \\
\text { Siwa; Ganesa, } \\
\text { Pratima }\end{array}$ \\
\hline 4 & Aksara & Sakral & $\begin{array}{l}\text { Suci, magis, } \\
\text { mistis }\end{array}$ & $\begin{array}{l}\text { Sebagai bagian } \\
\text { sarana upacara } \\
\text { keagamaan } \\
\text { (yadnya) }\end{array}$ & $\begin{array}{l}\text { Omkara, } \\
\text { Panca Brahma, } \\
\text { Panca Aksara, } \\
\text { Rerajahan }\end{array}$ \\
\hline 5 & Lambang & $\begin{array}{l}\text { Identitas } \\
\text { Agama Hindu }\end{array}$ & Suci & $\begin{array}{l}\text { Sebagai ciri } \\
\text { khas ke- } \\
\text { beradaan umat } \\
\text { Hindu }\end{array}$ & $\begin{array}{l}\text { Swastika, Pad- } \\
\text { mabhuwana }\end{array}$ \\
\hline 6 & Seni & $\begin{array}{l}\text { Identitas } \\
\text { budaya Bali/ } \\
\text { Hindu }\end{array}$ & $\begin{array}{ll}\text { Ada tiga : } \\
\text { - } & \text { Seni Wali } \\
& \text { (sakral) } \\
- & \text { Seni Bebali } \\
& \text { (semi } \\
& \text { sakral) } \\
- & \text { Seni Balih- } \\
& \text { balihan } \\
& \text { (profan) }\end{array}$ & $\begin{array}{l}\text { - Murni untuk } \\
\text { yadnya } \\
\text { - } \text { Sebagai ba- } \\
\text { gian dari } \\
\text { yadnya } \\
\text { - } \\
\text { Sebagai hi- } \\
\text { buran/ } \\
\text { rekreasi }\end{array}$ & $\begin{array}{l}\text {-Tari Rejang } \\
\text {-Tari Topeng } \\
\text {-Drama Gong }\end{array}$ \\
\hline
\end{tabular}

Klasifikasi Simbol_Simbol Hindu 


\subsection{Tentang Benda-Benda (simbol) Suci Menurut Pandangan Agama Hindu}

Perihal simbol, sebagaimana dipaparkan diatas, dalam Himpunan Keputusan Seminar Kesatuan Tafsir Terhadap Aspek-Aspek Agama Hindu (bagian 15), diklasifikasi sebagai benda-benda suci, yang penjelasannya sebagaimana dikutip seperti berikut :

\subsubsection{Pengertian}

Yang dimaksud dengan Benda-benda suci dalam Keputusan Seminar ini ialah : benda-benda yang memang disucikan dengan suatu upacara "pensucian" tertentu, yang fungsi dan penggunaannya semata-mata untuk tujuan suci dan ditempatkan pada tempat-tempat yang dipandang suci.

\subsubsection{Jenis/penggolongan}

Adapun jenis/penggolongan benda-benda suci yang dimaksud dalam pengertian tersebut di atas adalah : Pralingga, Arca, Pratima dan lain-lainnya yang semacam itu.

Dalam keputusan itu, bahkan juga disertai dengan langkah-langkah pengamanan, pencegahan dan penanghulangan agar tidak terhindar dari perbuatan/tindakan yang mengarah pada penodaan (simbol) agama, yaitu :

1) Pengamanannya :

Pengamanan benda-benda suci merupakan bagian dari kebijaksanaan pengamanan kebudayaan Nasional umumnya dan kebudayaan Bali pada khususnya secara pondamental dan menyeluruh.

2) Pencegahan:

(a) Meningkatkan kesadaran hidup beragama dengan menanamkan pengertian-pengertian hidup keagamaan secara konsepsional dan filosofis.

(b) Menanamkan pengertian tentang makna dan fungsi dari benda-benda suci dan penggunaannya dalam tata upacara Agama Hindu.

(c) Benda-benda suci patut ditempatkan/disimpan pada tempat suci dan terjamin keamanannya.

(d) Umat Hindu baik secara pribadi maupun secara berkelompok/bersamasama patut dan wajib ikut serta secara aktif mengawasi dan menga- mankan benda-benda suci.

3) Penanggulangan :

(a) Barang siapa yang ternyata menodai benda-benda suci dapat dipidana sesuai dengan ketentuan peraturanperundang-undangan yang berlaku.

(b) Dalam menjatuhkan hukuman pidana oleh Pengadilan (Hakim) hendaknya dipertimbangkan nilainilai kehidupan sepirituil sebagai unsur yang memberatkan atas penodaan terhadap benda suci tersebut.

(c) Apabila oleh yang bersangkutan (pihak yang merasa dirugikan) diajukan tuntutan perdata (gugatan) supaya dipertimbangkan nilai-nilai kehidupan sepirituil atas penodaan benda suci tersebut sebelum keputusan dijatuhkan.

Pada bagian 16 dari Himpunan Keputusan Seminar Kesatuan Tafsir Terhadap Aspek-Aspek Agama Hindu tersebut juga ditambahkan, tentang bagaimana caranya menjaga kesucian $\mathrm{Pu}-$ $\mathrm{ra}$ /Kahyangan, mengingat akan arti dan fungsi Pura sebagai tempat suci Umat Hindu, sehingga dipandang penting dikeluarkan keputusan "Tata Cara Masuk Pura" sebagai berikut :

a) Dilarang masuk Pura bagi orang-orang yang :

(1) Wanita dalam keadaan datang bulan, habis melahirkan dan habis abortus.

(2) Dalam keadaan sedang tertimpa halangan kematian (sebel).

(3) Tidak mentaati Tata Krama Masuk Pura.

(4) Menderita noda-noda lain yang karena sifatnya dapat dianggap menodai kesucian Pura.

(5) Menodai kesucian Pura (berpakaian tidak sopan, berhajat besar/kecil, bercumbu, berkelahi, mencorekcorek bangunan/ Pelinggih ).

b) Hanya orang yang terkait langsung dalam suatu upacara/ persembahyangan/piodalan dan atau kegiatan pengayoman $\mathrm{Pu}$ ra bersangkutan, diperkenankan masuk Pura sesuai dengan kedudukan dan fungsinya masing-masing, dengan tetap mengindahkan ketentuan-ketentuan larangan pada angka $1 \mathrm{di}$ atas. 
c) Orang yang tidak berhubungan langsung dalam kegiatan tersebut pada angka 2 di atas, dilarang masuk Pura.

Tata cara atau tata krama masuk Pura ini teramat urgen dibuat lalu disosialisasikan, dan tentunya dipatuhi, mengingat keberadaannya sebagai tempat suci (sakral) sekaligus sebagai simbol kesucian Hindu. Sudah sepatutnya, terutama oleh umat Hindu, dan juga pihak lain yang memanfaatkan Pura sebagai objek atau daya tarik wisata untuk bersama-sama menjaga kesuciannya. Sehingga apa yang disebut dengan tindakan pelecehan, penghinaan, penistaan atau penodaan simbol-simbol suci agama Hindu, se- dini mungkin bisa dicegah.

\section{PENUTUP}

Dengan mengetahui arti, bentuk, makna dan fungsi simbol-simbol keagaman Hindu sebagaimana terpapar di atas, diharapkan semakin jelas pemahaman umat dan juga pihak-pihak lain, lebih-lebih lembaga pemerintah agar dalam mengambil sikap, tindakan termasuk ketika mengeluarkan kebijakan yang berhubungan dengan pemanfaatan simbol-simbol suci agama Hindu, tidak terjadi penyimpangan atau pelanggaran yang bisa melukai perasaan atau emosi keagamaan umat Hindu.

\section{DAFTAR PUSTAKA}

Artadi, I Ketut. 2011. Kebudayaan Spiritualitas. Denpasar : Pustaka Bali Post.

Coulson, J.et.al. 1978. The New Oxford Illustrated Dictionary, Christian Brann Limited Cirencester, Englan.

Eliade, Mircea. 2000. Kunci-Kunci Metodologis dalam Studi Simbolisme Keagamaan, dalam Metodologi Studi Agama, Editor Ahmad Norma Permata Pustaka Pelajar, Yogyakarta.

Koentjaraningrat. 1980. Kebudayaan Mentalitet dan Pembangunan. Jakarta : Gramedia

Reede, J.J. De. 1989. Universal Symbolism, dalam Symbolism in Hinduism, Central Chinmaya Mission Trust Bombay.

Sivananda, Sri Swami. 1993. All About of Hinduism, diterjemahkan dalam Bahasa Indonesia Intisari Ajaran Hindu, oleh Yayasan Sanatana Dharmasrama, Surabaya.

PHDI. 1988. Himpunan Keputusan Seminar Kesatuan Tafsir Terhadap Aspek-Aspek Agama Hindu IXIV. Kuta : Peradah Komisariat Kecamatan Kuta

Parisada Hindu Dharma Indonesia. 2013. Swastikarana, Pedoman Ajaran Hindu Dharma.Denpasar : PT Mabhakti.

Sekhar Gosh, Ardhendu. 1990. Symbolism and Spiritual Wisdom, India's Life Breath, Bharatiya Vidya Bhavan, Bombay.

Soelaeman, M. Munandar. 2007. Ilmu Budaya Dasar, Suatu Pengantar. Bandung : PT Refika Aditama. Soekmono, R. 1973. Sejarah Kebudayaan Indonesia. Penerbitan Yayasan Kanisius.

Widana, I Gusti Ketut. 2012. Penjor Lebay. Denpasar : Pustaka Bali Post. 